\title{
学生事务与高等教育的改革与创新
}

\section{Higher Education Innovation, Reform and Student Affairs Work}

黄匡忠耶杰英蓝云剑 陈艳 Johnston Wong, Alex Kwong, Kenny Lan \& Joann Chen*

$\mathrm{H}$ IGHER education traditionally has organised its activities into "academic affairs" and "student affairs" . However, this dichotomy has little relevance to post-college life (ACPA, 2016). UIC, in line with the practices of $\mathrm{HKBU}$, aims to develop among our graduates seven attributes including many complex skills (e.g., leadership, creativity, citizenship, communication, team building etc. ) which needs to combine curricular contents and extracurricular experiences. Student Affairs Office (SAO) adopts a functional instead of structural organisation to facilitate professionalisation of student affairs personnel and innovations of service programmes. Clusters of student affairs projects are developed to promote 1) student self understanding, self control and self efficacy; 2) student social awareness, college engagement and servant leadership; and 3) student positive values, meaningful life goals and psychological resilience, to name a few more important objectives. The need for evidence-based planning and scientific evaluation of student affairs projects is fully recognised and viewed as an important strategy to build professional competencies of student affairs staff team. Last but not least the overall Mission of SAO is to build a caring and learning environment to enable student whole person development.

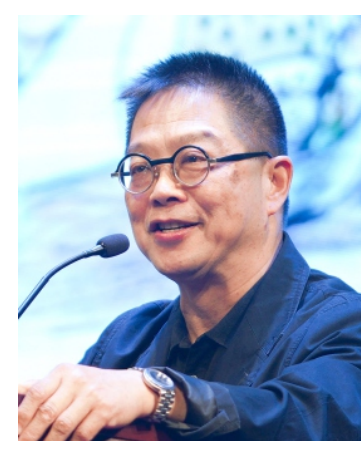

*黄匡忠，人文与社会科 学学部教授、学生事务 总监。

耶杰英, 学生事务处副 处长。蓝云剑, 学生事 务处助理处长。陈艳, 学生事务处高级主任。

Johnston Wong, Professor of the Division of Humanities and Social Sciences, Chief Student Affairs Officer.

Alexander Kwong, Associate Director of Student Affairs Office. Kenny Lan, Assistant Director of Student Affairs Office.

Joann Chen, Senior Administrative Officer of Student Affairs Office. 


\section{一、学生事务的教育任务：课堂内外 学习的结合}

学生事务是大学的核心工作之一。如何 在日常的学习生活中, 把大学的教育理念融

2018年3月16日，教育部部长陈宝生在 十三届全国人大一次会议后，回答中外记者 提问时表示：关于我们高等教育发展质量问 题, 我们是办四件事:

一是提升培养能力。学校办得好不 好, 能力十分重要。因为我们学校实际上 生产的是未来, 是人才, 为未来发展提供人 才支撑, 人才培养能力就是学校的生产力。 这是我们要办好的第一件事情。

二是要创新人才培养模式, 要适应我们 这个时代的需要。我们这个时代大家有很多 说法，信息化的时代、全球化的时代、新的 科技革命的时代，这一段时间人工智能异军 突起, 引起各方面的高度关注。这都要求我 们对人才培养的模式进行改革、进行创新。 这样我们才能培养承担民族复兴大任的一代 新人这样的历史任务。

三是要优化结构。要调整优化我们的学 科结构、专业结构, 让我们的高等教育能够 适应现代化建设的需要。你要为未来提供人 才, 就要紧盯未来, 你要为市场提供服务, 就要紧跟市场需求。所以就叫作跟着市场 调, 盯着未来走, 把我们结构搞优化。

四是要改革体制机制, 为培养新时代 需要的各种人才提供体制机制保证。总 之, 改革是未来教育发展的根本动力, 向改 革要动力, 是我们坚定不移的方针。(新华
网2018-03-16 10:31:21)

北京师范大学一香港浸会大学联合国际 学院 (以下简称北师港浸大) 是中国内地与 香港合办的一家实验大学, 肩负着替国家引 入国际化课程和国际化大学的管理模式、探 索中国高校如何吸收境外先进高校教育模式 的所长, 并与中国社会转型期的种种社会现 实状况相结合以推动我国高等教育的持续改 革的重任。

北师港浸大自2005年开办之初就考虑到 办学众多核心问题之一, 即如何展开学生事 务。从引入国际经验的需要而言, 我们引用 了香港浸会大学的宝贵经验。香港浸大成立 于1956年，已有63年的历史，其后接受香港 政府资助成为公立大学之一, 已褪去了宗教 色彩, 但仍保留着全人教育的传统和为社会 服务的精神, 其办学理念亦展示于其学生事 务工作之中。

香港浸会大学追求的毕业生特质 （Graduate Attributes）。浸会大学为其学 生最终的能力、行为和态度表现, 订立了七 项毕业生特质, 包括:

（1）公民 Citizenship

(2) 知识 Knowledge

(3) 学习 Learning

(4) 技能 Skills

( 5 ) 创意 Creativity

(6) 沟通 Communication

( 7 ) 群体 Teamwork

( HKBU Senate, 2008 )

高等教育的改革是与时俱进的, 每一个 变化都有特定的时代的使命与挑战。我们身 处的时代变化更是频繁。随着资讯科技的发 达与信息时代的来临, 大学教育的传统功能 已经丧失, 特别是单纯的知识传授。其实科 
学知识的快速更新换代, 在任何一个领域均 是如此，并不限于资讯科技领域。信息传递 的即时化和零成本化, 加速了其他科学领域 的知识和研究成果交流。以往一份实验报告 在学术期刊登载以后需要很长时间才能为人 认识和接受, 但今天在网上一公布发表以 后, 全球皆知, 复制研究和后续研究马上有 人开始。

科技教育的发展一日万里, 意味着人文 教育不可抱残守缺一成不变, 更不代表人文 教育不再重要, 反之是大学教育逐渐回归到 人文教育的怀抱。

北师港浸大亦同样以上述七项品质为毕 业生的表现标准。北师港浸大建校之初, 便 矢志成为我国内地第一所博雅大学。博雅大 学在美英欧洲等地均有悠久的历史和传统, 北师港浸大亦于建校初期便与美国众多博雅 大学建立紧密联系, 举办教职员交流, 安排 学生前往世界各地进行暑期学习, 也安排学 生以交换生身份在很多历史悠久的大学学习 半年。

我们设计北师港浸大的学生工作时其实 是兼收并蓄, 尽取各家之长而不拘一格, 而 且我们的目光没有受限于香港一地, 而是把 视线投向国际高等教育改革的讨论。高等教 育重视老师的“教”，但评估教学的表现在 于学生的 “学”, 高等教育的质量考核, 已 产生了范式的转变。从上述香港浸会大学的 七个毕业生特质可见很多能力已经不是传统 课堂授课可以达到, 必须让学生参与讨论, 分析案例, 进行主题研究, 作学术报告, 从 而实现前文陈宝生部长所提出的“提升培养 学生能力”。如果要培养大学生的公民意 识, 沟通能力与群体精神, 更要走出课堂, 进入生活。

高校学生事务的教育功能, 就是要打
破课内与课外的藩篦, 结合书本与社会实践 的学习。学生社团和宿舍生活就是大学生社 会实践最直接的平台, 学生事务就是要充分 利用这两大平台来设计学生活动, 发挥我们 的教育功能。学生事务的教育任务就是透过 设计课外的活动, 呼应课堂上知识的传授, 以完成学校教育的目标, 特别是毕业生特质 的内容。

\section{二、学生事务体制的创新与专业化}

我国高校的学生事务架构, 多是配合着 大学及下属各学院来建立的, 亦即由大学至 学院至各学科再分年级, 然后按学生人数的 一定比例, 配备学生“辅导员”, 或称班主 任老师。辅导员一般与学生共同生活在同一 宿舍, 按年级和性别分开楼栋和楼层, 很多 辅导员也是由同校的研究生担任。

这种学生处组织或称之为“架构性分 工”，其实有很多好处。一方面辅导员与学 生年纪相近, 容易理解和沟通。学生在学业 上生活上有什么问题, 都会向辅导员即班主 任提出。但很多高校由于资源的限制, 往往 学生相对辅导员的比例较高, 而且学生无时 无刻可以联系辅导员也让“班主任”不堪负 荷, 如果辅导员也在读研, 压力可想而知。 在人力资源充足之下架构性分工并无不妥, 这传统的体制在过去十年相信已有不少变 革, 例如很多高校都会另行设立专业的学生 心理辅导中心, 或由学生当中选出房长及层 长以配合和减轻辅导员的日常琐碎事务。有 些高校亦尝试推行学生朋辈辅导, 以补充辅 导员制度的人力和社交资源。当然学生事务 处亦会使用学生志愿者或透过勤工俭学方式 减轻人手不足的工作压力。 
北师港浸大创建学生事务处之初, 引入 了创新性的体制, 或称之为“功能性分 工”。我们在这方面是以哈姆林大学 (Hamline University)的学生事务工作为坐标 (Benchmark)。美国哈姆林大学学生事务 处有精密的架构, 而不同部门也有详尽的工 作程序, 我们的同事前往学习后均有很高的 赞誉。该大学有超过一百年的历史, 人文精 神沉凝厚重, 作为一所博雅大学哈姆林大学 处处折射出以学生为中心的大度。有几点印 象尤为深刻, 首先是该校所有部门的网页都 会展示该部门的使命和愿景, 部门的使命和 愿景又与该大学的使命和愿景互相呼应。 (Hamline University Student Affairs Office, 2017)

所以, 我们要学习的第一件事情就是订 立北师港浸大学生事务处的使命和愿景, 现 载于下:

\section{(1) 我们的愿景:}

贯彻北师港浸大博雅教育的理念, 推行 全人教育, 建设终生学习社区。

(2) 我们的使命:

致力建立一个理性与关怀的生活和学习 空间, 建设一个传承文化与思考未来的终生 学习社区, 鼓励同学参与社会, 在课堂外尝 试待人接物的生活经验和建立关怀的信念, 提供各种活动资源及信息, 培养学生成为具 有卓越才能和国际视野的服务型领袖。

因此, 北师港浸大学生事务处设立了四 个功能性工作组, 即 :

（1）服务型领袖发展组;

(2) 学习型社区发展组;

(3) 个人成长及辅导组;

(4) 学生支援服务组。

功能性分工的体制, 可以让我们的工作 更为专业化。
例如服务型领袖发展组, 致力于同学组 织能力、解难能力、社交能力、演辩能力、 理财能力、宣传能力等方方面面的培育, 中 外均有非常多系统化的课程可以参考, 也有 无数的青年研究可以指导我们的工作。

又以个人成长及辅导组为例, 我们的专 业辅导员都必须要接受应用心理学、心理辅 导学或社会工作学硕士或以上课程的训练, 也是一种专业性的工作。

我们认为宿舍不应是学生单纯生活的地 方, 更是学习的地方, 是促进师生共同学 习, 分享交流的地方。在宿区, 老师可以打 破课室的局限, 与学生在一个自然的气氛下 交流和分享人生。学习型社区发展组援引英 国高等教育“舍堂文化” ( Hall Culture) 的 传统, 设立了八个舍堂, 即: 博雅苑、创雅 苑、文雅苑、德雅苑、科雅苑、卓雅苑、智 雅苑及睘雅苑。每个舍堂我们委任了一位教 学人员担任舍监, 作为学生的精神领袖, 舍 监在学生事务处的同事及苑舍学生会的协助 下, 开展各种中小型文娱及学习活动, 以丰 富学生的苑舍生活, 让学习生活化, 让生活 学习化。例如, 我们都知道大学应该注重培 养学生强健的体魄, 这不能仅依靠体育课来 进行, 而苑舍活动正好是一大助力。

要进行非正规教育, 理论上在校园内任 何地方都可以进行, 例如公园或餐厅。但这 些环境却并非 “有组织但非正规教育” 的理 想场所。北师港浸大为此特别设计和兴建了 两所“师生活动中心”, 由学生支援服务组 负责管理。在中心内学生可分区进行活动: 自行休息、讨论作业、看书、听音乐等。学 校所有老师及社团学生干事, 均可借用场地 作为生日会、茶会、研讨会、电影放映会等 活动。一些老师会定期进行新闻评论会、文 学欣赏会, 或其他兴趣活动, 内容多种多 
样。学生支援服务组还负责奖助学金、勤工 俭学、学生档案、导师关顾计划等, 范围广 泛。

四个功能性工作组之外, 我们还设立了 学生助理处长 (纪律) 和学生纪律专责导 师, 对应学校纪律委员会所需前期的取证工 作和事后决定的执行。纪律工作重在预防, 由学生协助进行守规教育, 推动法治精神。

\section{三、学生服务内容的创新与科学化}

学生事务处体制的创新, 带来了服务的 创新。以下我们以三个方面的工作显示专业 化的服务如何更科学化, 更有效果。

\section{1. 自控力，自我效能感与学业表现}

Walter Mischel (1976) 的“棉花糖实 验” 针对学龄前5岁幼童进行, 通过用棉花糖 测孩子的自制力。若他们能够忍耐 20 分钟不 吃掉面前的棉花糖, 便可以多得一颗作为奖 赏。后续的追踪研究发现, 那些能够抗拒马 上吃糖的冲动、忍受煎謷的实验并获得第二 颗糖的孩子，在青春期阶段不论学业或 是社会能力皆较同侪为佳。Hirschi \& Gottfredson (2000) 将自我控制的发展主要 归因于幼儿期的学习, 大约在八岁到十岁之 前。一旦学习了自我控制, 理论上在整个生 命周期中会保持相对稳定。童年的经验会影 响日后的自我控制; 一个人的亲社会或反社 会行为倾向是由他/她所经历的胁迫或社会支 持的一致性所决定的，一致的社会支持可产 生高度的“内化的自我控制感”。

学生事务处利用新生军训，实行意志力
团队训练的制度, 推行为期五天的锻炼和自 控力工作坊。

全体新生会分为大概 50 人一排, 进行三 小时的理论学习, 课程内容着重介绍自控力 对个人的重要性。理论课后由教官们加以团 队队形训练, 又类似集体操的演示。人类因 习惯、心理差异, 而造成强度不一的意志 力。在一定的时期或在某种情况下以理性行 事而不以情绪行事, 最终目标才可达成, 正 如运动可以使肌肉变得更强壮一样, 经常运 用自我控制可以提高意志力 (Mcgonigal，K., 2012)。此外, 改善姿势, 改变言语行为, 练 习执行一个简单的任务, 都可作为改善自我 控制的第一步。

研究发现自控力跟学习有着很强的相关 性, 更可预测年轻人的学业成绩, 生活上的 平衡及流动。低自控则容易影响个人决定, 不懂跟人沟通，做出犯罪行为。

因此自我控制是学习成绩、生活平衡和 青少年流动的预测指标 (Kuhnle \& Hofer, 2012)。选择合适的目标，适当地预算时间和 精力, 在决策阶段和行动阶段中, 自我控制 能力有助于选择和追求一个既定的行动计 划, 以便成功达成一个目标。在追求所选择 的活动（行动阶段）期间，对结果的渴望有 助于控制冲动, 避免影响心理过程, 有效将 注意力集中在手头的任务上。因此在学业与 休闲需求产生冲突时, 时间管理便成为一种 自我控制能力的具体表现。

自我控制的研究引申出自我效能感的 思考。

自我效能感是Bandura社会认知理论和 社会学习理论中的核心概念, 它直接影响人 们的思维、动机与行为 (Bandura,1986)。自 我效能感是指人们对自己实现特定领域行为 目标所需能力的信心或信念, 是指个人对自 
己在特定情景中是否有能力去实现行为的期 望, 是人对自己行为能力的一种主观推测、 对自己的一种主观评价与认识; 它包括了对 自己的行为所产生的结果进行推测, 并对自 己是否有能力进行这一行为做出推测、判 断, 或者说是对主体的自我把握与感受。 (Bandura, 1977)

在学习方面, 自我效能感水平高者倾向 于选择适合自己能力水平的学习目标, 能有 效控制自己的学习行为。这理论着力提升青 少年内部动机; 因此, 我校提倡培养学生的 自我效能, 尤其在学习动机较低的学生身 上, 以辅导形式提升学生学习效能感, 使学 生形成自我效能感并改变学习方式。

学业自我效能感是自我效能感在学习领 域内的表现, 提升自我效能感能够促进学业 成绩提高。学生事务处尝试把辅导及学业自 我效能感的理论结合, 积极提升学生的学习 动机, 促进学业成绩提高; 以单对单辅导形 式, 让个人的自我效能感得到提升, 面对学 习的挑战。我们进行了随机对照前后测的研 究, 效果良好 (陈、萧、黄, 2016)。

\section{2. 服务型领导力与学生校园投入}

\section{（1）培养服务型领导力的平台}

我校的学生组织包括学生会、宿生会、 专业学会, 还有各类的兴趣社团 60 多个, 给 培养学生领袖创造了优越的平台。结合北师 港浸大全人教育的发展, 学生事务处广泛推 行和提倡服务型领袖的成长理念, 在学生社 团的活动及学校大型活动中有目的性地引导 学生领袖树立以人为本, 为广大同学服务的 观念, 以培养融合博雅教育及具有卓越才能
及正确价值观的优秀服务型领袖为整体目 标。在学生社团中, 北师港浸大为学生创造 和提供很多实践的机会, 学生校园投入 (Student Engagement) 能发展个人多方面 的领导才能 (Servant Leadership)。通过 组织各类型的活动培养团队合作的能力, 培 养独立思考问题和解决问题的能力, 从而能 对身边各种问题做出正确的判断和评价, 让 学生领袖的整体素质都能得到提升。

“服务型领袖”一词最早出现在罗伯 特・格林里夫 (徐放, 齐贵萍, 2008 ) 撰写 的一篇名为“领导即服务”的文章里。他认 为服务型领袖是那些能把他人的需求、愿望 和利益放在自身利益之上的领导者, 是那些 首要动机是服务他人而不是领导和控制他人 的领导者。国内研究者倪健新( 倪健新, 2009 ) 提出, 作为代表人本管理思想的服务 型领导，其管理模式应该一种自下而上的倒 金字塔型的管理模式, 满足员工（内部顾 客) 成长发展的需要为企业管理的重心, 企 业应以提供的产品或劳务让外部顾客(用 户 ) 满意为工作的目标。

根据Spear (Spear L.C.,1995) 的总 结, 服务型领袖理论已经在以下六个领域产 生了重要影响:

(1) 成为部分组织的领导哲学;

(2) 成为培训董事会成员、非营利组 织负责人等“信托人教育”的重 要课程;

(3) 应用于培训社群领导的项目;

(4) 应用到 “干中学” 的教学项目, 通 过引导学生参与社会服务来学习有 用的社会经验和知识;

(5) 成为大学和企业管理教育和培训 的重要课程;

(6) 应用于促进个人成长的培训项目。 


\section{（2）服务型领袖培训的内容与载体}

服务型领袖提倡服务为先, 领袖先做众 人的仆人, 给他人以关爱, 接纳他人。

根据研究, 服务型领袖应有以下10项领 导能力 ( 徐放, 齐贵萍, 2008 ) :

( 1 ) 聆听（Listening）。服务型领袖以 对方为优先, 定意要透过用心聆 听, 触及别人的心灵, 了解对方的 想法和需求。聆听, 并伴以经常性 的反思, 对服务型领袖来说, 非常 重要。

(2) 同理心 (Empathy)。服务型领袖 尝试了解与同情对方, 关注的不再 是个人荣辱得失, 而是接纳与肯定 团队内其他成员付出的辛苦, 并予 以欣赏。

（３）自愈（Healing）。疗伤之道是服务 型领袖的强大武器, 能够帮助他们 跨越过渡转型、重组整合的各个艰 难时期。服务型领袖的一项强大之 处就在于他/她能够帮助他人以及他 自己疗伤，一位经历过伤痛并已痊 愈的领袖正是人们所期待的。

(4) 觉醒 (Awareness )。觉醒, 尤其 是自我觉醒是服务型领袖的另一显 著特征，他/她不会陶醉于过去或现 在的成功, 他/她知道有些时候需要 被挑战, 受搅动, 才不会安于现 状。

（5）说服（Persuasion）。服务型领袖 不是仗着职权或威信来统御, 而是 以“动之以情, 晓之以理, 析之佐 据”的说式，劝服别人认同计划或 工作，让人心服 $\square$ 服，而不是勉强
为之。

（6）概念化 ( Conceptualization )。服 务型领袖敢于做梦, 对他/她来说, 再过夸张的梦想亦有成为现实的可 能。尽管他/她的想象力天马行空, 但在处理问题时，却能脚踏实地， 他/她能够巧妙地平衡 “概念化” 的 意向与日常事务的现实情境，两者 皆为必需。

（7）先见(Foresight）。人非圣贤孰能 无过，服务型领袖也会犯错误，但 他/她却能够从实践中不断汲取教 训, 在行动中做出反思, 从而获得 对未来行为决策的先见。

（8）管家 (Stewardship）。人们所求于 管家的, 是要其有衷心。服务型领 袖就怀有管家的衷心，为组织内成 员服务，为组织所处的社区服务。

(9) 促进他人成长 (Commitment to the Growth of People )。服务型 领袖用心帮助组织内的每一位成员 成长，使人更强壮、更聪慧、更自 由、更自主。

（10）构建社群（Building Community）。 服务型领袖不会 “一将功成万骨 枯”，他/她要构建生生不息、基业 长存的社群，并工作、服务于 其中。

提高学生领袖如上述的领导力，要有系 统地持续地进行培训，领导力训练营 (Leadership Camp) 是学生事务处在领 袖发展工作从无到有创办的新载体。学生服 务型领袖发展组每学期都举办领导力培训营 Level 1及Level 2，旨在培养学生领袖正确 
的思维方法，培养学生领袖敏锐的观察 力，培养学生领袖全局的眼光，开拓学生 领袖的视野，培养探索创新精神。领导力 培训营通过团队建设、拓展活动等活动形 式，有目的性的团队合作激发学生的领导 力，通过团队合作激发成员的责任感及认 同感。2019年上半年我们办了Level 3，下 半年第一次举办Level 4 。

\section{（3）服务型领导力的痕迹与认可}

为了鼓励学生积极参与丰富多彩的课外 活动, 同时也方便记录学生课外活动的参与 度, 学生事务处设计了一项 “学生领袖发展 路径” (Leadership Path) 的奖励计划。学 生在社团任职, 每次参与不同类型的课外活 动都能获得相应的积分, 系统地记录在学生 的电子成长档案 (Leadership Development Portfolio), 相当于课外活动成绩单, 为学 生之后的深造学习或工作提供证明材料。

同时, 学生领袖成长档案将累计每位学 生的积分, 达到不同的分数可获铜章奖、银 章奖、金章奖或钻石章奖, 以表彰学生在学 生领袖方面及课外活动方面所获得的成果及 对校园文化的贡献。

\begin{tabular}{|l|c|c|}
\hline 奖项 & 2017年 & 2018年 \\
\hline 钻石章奖 & 7 & 12 \\
\hline 金章奖 & 23 & 43 \\
\hline 银章奖 & 168 & 144 \\
\hline 铜章奖 & 565 & 404 \\
\hline
\end{tabular}

学生领袖奖项获得者的人数

北师港浸大鼓励学生参加社会实践活动 及义工服务。每年暑期, 很多学生通过参加
支教活动、社区义工服务、海外义工服务来 增强自己的社会责任感, 提升自身的领导能 力。我们鼓励学生领袖积极参加各类国际组 织举办的活动或研讨会, 让学生领袖能通过 与不同文化背景及兴趣的人交流, 分享对事 物的不同见解, 培养创造性的思维, 加强与 其他成员合作的技能, 明确自己肩上的责 任, 充分发掘自己的潜力, 使自身在个人发 展及领导力方面获得迅速成长, 成为一个具 有开放胸怀和全球化视野的优秀世界公民。

一项调查收集了200份关于领导力实践 的问卷, 其中99位受访者未在学生组织中担 任领袖, 101位受访者曾在学生组织中担任 一个或一个以上的职位。经过分析数据, 在 Martin Seligman (Peterson, C., \& Seligman, M. E.P., 2001)) 设计的24性格优 势 (Character Strengths) 中, 曾在学生组 织中担任领袖相对于从未在学生组织中担任 领袖的受访者, 在善良、公正、判断力、开 放性思维、对未来的展望及感恩等五种性格 品质中表现得更好, 在统计学上有显著的分 别。( Lin Tianjing，2017) (礼铃胡, 2013 )

\section{（4）性格优势，抗逆力与生涯规划}

人的一生中充满了各种各样的压力与困 境, 是否拥有良好的抗逆力在一定程度上将 决定你生活的质量与人生的价值。大学作为 一个重要的人生阶段, 同样充满了各种逆境 与挫折。随着改革开放, 中国社会开始转 型, 社会风险日益增多, 如何培育年轻一代 具备面对逆境以及适应逆境的能力, 成为大 学教育关注的重点。

“抗逆力”来自英文的 “Resilience”， 原意是指弹力、恢复力, 后被引入到心理学 
研究中, 表示个体用来保护和抵抗各种挫折 和困难的潜力和能力。

Wagnild (2010) 指出人们会用不同的 方式回应逆境, 可总结为五种基本特征: 了 解生活的目的，不放弃的毅力，对自己的信 心, 应对逆境时的平和, 以及回归内心的能 力。这五种特征可被归纳为三大要素: 韧 性、个人能力和乐观心态。韧性指的是在经 历逆境时, 个体表现出的平静、对情感的控 制; 个人能力主要强调个体从逆境中恢复、 重建的能力。

抗逆力既被定义为适应逆境的一种能 力，即在困境中也不会被压倒的“品质”， 这是一种过程, 也可以是一种结果。抗逆力 不能被直接量度, 而是通过观察个体在经 历逆境后的积极反应进行推测。但马 斯滕 ( A.S.Masten ) 和科斯特沃斯 (D.Coastworth) 则认为, 不能将抗逆力 视为个体的一种固定品质, 因为面对不同的 环境和危险，抗逆力也会有不同的表现，所 以应该视抗逆力为一种良好的适应, 是在某 一时点上, 危险因素和保护因素相互影响博 弯的过程。与抗逆力紧密相关的两个概念 是：风险因素 (Risk Factors) 和保护因素 (Protective Factors)。正是由于风险因 素的存在, 个体才能展示出其抗逆能力。

马斯滕等提出风险/保护因素来自三个 方面:

（1）个人层面的，包括一些基本的个体 特质，如智力水平和性格等;

（2）家庭层面的，包括家庭本身的特质 以及家庭可以给予孩子的支持、家 庭的情感互动;

（3）外部支持层面的, 包括能够协助儿 童和家庭的, 在个体和家庭之外的
其他任务和制度的外部支持 ( Masten, A. S.et al., 1999)。

乐观心态则体现个体在逆境中对自身恢 复和追求生活目的的信心。这与现代心理学 的正向学派 (Positive Psychology) 崛起互 为呼应。Martin Seligman (Peterson, C., \& Seligman, M. E.P., 2001)) 提出了“性格优 势” (Character Strengths) 的理论, 认为 24种性格优势也可名为行动中价值 (Values in Action ), 会为人们带来 “原本的快乐”

(Authentic Happiness)。而这24种性格优 势被归纳为 6 大美德: 智慧与知识、仁爱、公 义、勇气、节制、灵性与超越。

传统的青年发展研究是问题取向 (Deficit-Orientation) 的, 关注如何防止青 少年犯错。反之, 近代抗逆力理论 (Resilience) 采用了优势视角 (Strength Perspective ), 引导研究者关注风险中的个 体和组织的社会资本和能力, 是 20 世纪70年 代以来大学教育工作者的重要理论和实践指 引（刘玉兰，2013）。

为研究我校同学在抗逆力方面的表现与 性格优势的关系，学生事务处收集了2016和 2017年应届准毕业生的数据。研究内容包括 学生校园投入度的变项等。

这次的调查一共收集到有效问卷有 1361份，429人 ( $31.52 \%)$ 为男生，932人 (68.48\%) 为女生。整份问卷的克隆巴赫系 数 (Cronbach's Alpha) 为0.974, 抗逆力部 分为 0.932 , 性格优势部分为 0.965 。伟纳抗 逆力 25 题 ( R25 ) 的平均值为 95.28 , 平均得 分率为 $76.22 \%$, 性别差异不显著。

在24种性格优势的六个美德中，仁爱、 灵性与超越和节制这三个美德得分较高, 且 性格优势得分受性别的差异性小。性格优势 
与自我抗逆能力有着显著的相关性, 因而培 养学生积极心理和发展各项性格优势有助于 提高他们的抗逆能力。与抗逆力得分相关性 较高的美德为智慧与知识、勇气、灵性与超 越三项, 具体内容是: 创造力、好奇心、开 放性思维、好学、洞察力、勇敢、毅力、正 直、热情、对美和卓越的欣赏、感激、希 望、幽默、信仰。

学生校园投入度与抗逆力也呈现较为显 著的相关性, 意味着更多的校园活动参与, 如学术活动、志愿者活动、兴趣社团等, 亦 有助于大学生抗逆能力的提高, 例如: 志愿 者活动与抗逆力的相关性是 $r=0.261^{*}$ * , 即 轻微相关。我们仍需探索哪一类活动能有效 提高抗逆力。

北师港浸大超过六成学生都准备毕业后 就读硕士课程, 所以帮助同学认识个人的职 业方向相对于就业安排而言更为重要。

学生事务处执行了多年, 让大一所有同 学填写“霍兰德职业能力人格”问卷 ( Holland's Career Keys Analysis), 然后 自行分析结果。但这项自评活动未能发挥职 业发展指引的效果, 一方面由于新生对就业 未有那么长远的考虑, 另一方面可能是霍兰 德的职业能力人格理论 ( Career Personality Types Theory) 的失效, 因为科技的急速发 展, 职业市场生态千变万化, 个人性格与就 业市场根本无法进行配对 ( Holland, 1997 )。

取代职业能力人格理论而兴的是社会认 知职业理论 (Social Cognitive Career Theory -SCCT )。该理论提出职业是一个发展与成 长的过程, 影响职业发展的有三个要素: 自 我效能感（Self-efficacy beliefs）、结果期望 值 (Outcome Expectation) 和目标 (Goal) 的订立。 ( Lent, Brown, \& Hackett, 1994 )
SCCT也是从班杜拉 (Albert Bandura) 的社 会认知理论 ( Social Cognitive Theory) 延伸 而来。

应用社会认知职业理论, 学生事务处在 大学之道课程内容上已提供了认识自我 (Knowing Self)、制定目标 (Setting Goals) 和书写人生 (Authoring Life) 等课 程, 但要有后续的跟进才能发挥效果, 所以 从二年级要考虑提供“职业生涯规划”的 辅导。

总结而言, 性格优势、生涯规划与抗逆 力的培养, 是并行而互相推进的。而校园参 与 (如课外活动) 是对三者都有利的中介 因素。

\section{四、学生事务工作的创新与团队的优 秀化}

\section{1. 新时代的学生工作目标}

我校学生事务的未来, 有以下的优先 原则:

（1）着重培养学生的个性和自主性, 协 助学生寻找真我 (Identity and Autonomy); 培养学生的自控力 和抗逆力, 以面对社会的急速转型 (Will power and Resilience);

(2) 培养学生的人文精神、社会责任感 和家国情怀, 以服务人群为己任 ( Humanism, Social Responsibility and Global Citizenship );

(3) 培养学生传承中国传统文化, 追寻 传统美德 (Chinese Heritage and Traditional Virtues ) ; 
（４）鼓励学生学习世界文化, 包容不同 生活习惯, 建立社会和谐共融 (Cultural Diversity and Social Inclusion ) ;

（5）引用中国传统文化的精髓, 即天人 合一, 在运动和大自然中追求身心 灵的平衡 ( Naturalism and Holistic Health )。

在北师港浸大的硬件大幅度完善之下， 学生事务处的工作也适宜追上创新的步伐, 再次探讨未来的方向。

新的愿景可以由2018-2019学年为起 点, 为未来五至十年的学生事务工作做出 规划。

在学生事务工作的成效即学生非学习而 言, 我们认为可以修订愿景如下:

( 1 ) 为贯彻北师港浸大博雅教育的理 念, 推动师生建设终生学习型社 区。

（２）未来五至十年内, 我们的师生在学 生事务处的推动下, 将积极推动珠 海公益事业，主办及参加粤港澳台 地区青年交流，为中国内地以至一 带一路地区主办及参与社会及文化 交流活动，并设计社会创新构思， 以协助解决区域性的社会问题。在 过程中也让同学学习如何成为服务 型领袖。

\section{2. 新时代的学生工作队伍}

在学生事务的工作团队建设方面, 我们 可以制定副愿景如下：我们在未来五至十年 内建立一支热诚、关爱同学、具有专业知 识、有社会理想，愿意结合所学投入社会创
新, 为珠海、粤港澳大湾区以及中国内地社 会及社区出谋献策，改善人们生活而努力不 懈的队伍。我们相信互动（Interaction）会 带来创新 (Innovation) 和带来社会影响力 (Impact-Action)。

美国高校工作者协会 (American College Personnel Association-ACPA) 发表了《学习的再思》( Learning Reconsidered $1 \& 2$ ) 的报告, 提出高校工 作者的新的胜任力 (Competencies) 要求。 ACPA提出高校辅导员十个能力范围：

（1）咨询与帮助（Advising and Helping )

(2) 评估与研究 (Assessment, Evaluation, and Research )

(3) 平等, 多元与包容 (Equity, Diversity and Inclusion )

(4) 专业道德操守 (Ethical Professional Practice )

(5) 历史, 哲学, 价值 ( History, Philosophy and Values )

(6) 人力与组织资源 (Human and Organizational Resources )

( 7 ) 政府, 政策与法律 ( Law, Policy and Government )

( 8 ) 领导力 ( Leadership )

(9) 个人素质 (Personal Foundations)

(10) 学生学习与成长 (Student Learning and Development )

我们为了提升学生事务工作人员的胜 任力 (游梦佳, 2016)，每年都邀请境内 外学者来校举行系统培训, 并从2016年开 始也开放让港澳与内地同行参加。下一个 阶段我们的策略是“调查研究为推动, 实 证为本为目标"。在 


\section{部分参考文献}

- $\quad$ ACPA, Learning Reconsidered One and Two. http://www.myacpa.org/learning-reconsideredone-and-two

- Bandura, A. (1977). Self-efficacy: Toward a unifying theory of behavioral change. Psychological Review, 84, 191-215.

- Bandura, A. (1986). Social foundations of thought and action: A social-cognitive view. Englewood Cliffs, NJ: Prentice-Hall.

- Hamline University, (2016). Student Affairs Division has the primary responsibility to make the out-ofclassroom environment an integral aspect of student's education.

Extracted from http://www.hamline.edu/ offices/provost/student-affairs/

- Hirschi, T\& Gottfredson, M. R. (2000). In Defense of Self-control. Theoretical Criminology, 4(1), 55-69.

- HKBU Senate (2008). HKBU Graduate Attributes, Centre for Holistic Teaching and Learning, Hong Kong Baptist University. Extracted from http://chtl.hkbu.edu.hk/main/hkbu-ga/"

- Holland, J. L. (1997). Making vocational choices: A theory of vocational personalities and work environments (3rd ed.). Odessa, FL: Psychological Assessment Resources, Inc.

- Kuhnle, C. \& Hofer, M. (2012). Self-control as predictor of school grades, life balance and flow in adolescents. British Journal of Educational Psychology, The British Psychological Society, Volume 82, Issue 4, 533-548.

- Lent, R. W., Brown, S. D., \& Hackett, G. (1994). Toward a unifying social cognitive theory of career and academic interest, choice, and performance

- Lin, T. J., (2017), UIC Students as Leaders in Extracurricular Activities: Influence on Character Strengths, unpublished Final Year Project, BNUHKBU United International College, Social Work and Social Administration Programme.

- Masten, A. S.et al., (1999). Competence in the context of adversity: Pathways to resilience and maladaptation from childhood to late adolescence. Development and Psychopathology,
11 (1999), 143-169.

- Mcgonigal, K. (2012). The willpower instinct: how self-control works, why it matters and what you can do to get more of it. USA: Penguin Group Inc.

- Mischel, W. (1976). The Marshmallow Test, Why Self Control is the Engine of Success. Little, Brown \& Company: New York, Boston, London.

- Peterson, C., \& Seligman, M. E.P.(2001).VIA Inventory of Strengths (VIA-IS).

Retrieved March 26,2017 from:

http://www.positivepsychology.org/viastrenghtsi nventory.htm .

- Spear, L.C. (1995), Reflections on Leadership: How Robert K. Greenleaf's Theory of Servant Leadership Influenced Today's Top Management Thinkers. Servant Leadership and the Greenleaf Legacy, New York: John Wiley \& Sons.

- 王克 (2011)。《优势视角下的当代大学生抗 逆力状况研究》。西北大学。

- 王学臣, 周琰 ( 2008 )。大学生的学习观及其 与学习动机、自我效能感的关系。《心理科学》, $31(3), 732-735$ 。

- 陈雪军, 萧美玲, 黄匡忠 (2016)。利用辅导 提升自我效能对学业提升的影响, 《教育教学论 坛》，2016年3月6第期，6-7。

- 刘玉兰 (2013)。西方抗逆力理论: 转型、演 进、争辩和发展。《国外社会科学》, 6, 6774 。

- 徐放, 齐贵萍 ( 2008$)$ 。《仆人领导》 （译），原著者罗伯特・K.格林利夫 ( Robert K.Greenleaf )，江西人民出版。

- 倪健新（2009）。浅析服务型领导及其在中国 企业的应用[J]，《管理观察》, 88-89。

- 游梦佳 ( 2016) 。来华留学生辅导员职业能力 及提升研究。《科教导刊》, 2016(17), 158159 。

- 礼铃胡 ( 2013 )。《领导力实践问卷: LPI》, 译, 原著者詹姆斯.M.库泽斯, 巴里.Z.波斯纳。

- 新华网（2018）。两会教育部, 《努力让每个 孩子都能享有公平而有质量的教育答记者问》, 2018-03-16 10:31:21. 资料来源： https://www.guancha.cn/politics/2018_03_16_4 50378 s.shtml 